\title{
Iron-dependent nitrogen cycling in a ferruginous lake and the nutrient status of Proterozoic oceans
}

\author{
Céline C. Michiels ${ }^{1}$, François Darchambeau ${ }^{2}$, Fleur A. E. Roland ${ }^{2}$, Cédric Morana ${ }^{3}$, Marc Llirós ${ }^{4,5}$, \\ Tamara García-Armisen ${ }^{6}$, Bo Thamdrup ${ }^{7}$, Alberto V. Borges ${ }^{2}$, Donald E. Canfield ${ }^{7}$, Pierre Servais ${ }^{6}$, \\ Jean-Pierre Descy ${ }^{8}$ and Sean A. Crowe ${ }^{1 \star}$
}

\begin{abstract}
Nitrogen limitation during the Proterozoic has been inferred from the great expanse of ocean anoxia under low- $\mathrm{O}_{2}$ atmospheres, which could have promoted $\mathrm{NO}_{3}{ }^{-}$reduction to $\mathrm{N}_{2}$ and fixed $\mathrm{N}$ loss from the ocean. The deep oceans were Fe rich (ferruginous) during much of this time, yet the dynamics of $\mathbf{N}$ cycling under such conditions remain entirely conceptual, as analogue environments are rare today. Here we use incubation experiments to show that a modern ferruginous basin, Kabuno Bay in East Africa, supports high rates of $\mathrm{NO}_{3}{ }^{-}$reduction. Although $60 \%$ of this $\mathrm{NO}_{3}{ }^{-}$is reduced to $\mathrm{N}_{2}$ through canonical denitrification, a large fraction $(40 \%)$ is reduced to $\mathrm{NH}_{4}{ }^{+}$, leading to $\mathrm{N}$ retention rather than loss. We also find that $\mathrm{NO}_{3}{ }^{-}$reduction is Fe dependent, demonstrating that such reactions occur in natural ferruginous water columns. Numerical modelling of ferruginous upwelling systems, informed by our results from Kabuno Bay, demonstrates that $\mathrm{NO}_{3}{ }^{-}$reduction to $\mathrm{NH}_{4}{ }^{+}$could have enhanced biological production, fuelling sulfate reduction and the development of mid-water euxinia overlying ferruginous deep oceans. This $\mathrm{NO}_{3}{ }^{-}$reduction to $\mathrm{NH}_{4}{ }^{+}$could also have partly offset a negative feedback on biological production that accompanies oxygenation of the surface ocean. Our results indicate that $\mathbf{N}$ loss in ferruginous upwelling systems may not have kept pace with global $\mathrm{N}$ fixation at marine phosphorous concentrations $(0.04-0.13 \mu \mathrm{M})$ indicated by the rock record. We therefore suggest that global marine biological production under ferruginous ocean conditions in the Proterozoic eon may thus have been $\mathbf{P}$ not $\mathbf{N}$ limited.
\end{abstract}

A $s$ an element essential to life, nitrogen $(\mathrm{N})$ often limits biological production ${ }^{1}$. $\mathrm{N}$ is made available to life through microbial fixation of atmospheric $\mathrm{N}_{2}$. This $\mathrm{N}$ is liberated as $\mathrm{NH}_{4}{ }^{+}$from decaying biomass, and oxidized to $\mathrm{NO}_{3}{ }^{-}$in the presence of oxygen. $\mathrm{N}$ is returned to the atmosphere through $\mathrm{NO}_{3}{ }^{-}$reduction to $\mathrm{N}_{2}$ under low $\mathrm{O}_{2}$ conditions. Two microbial processes are responsible for $\mathrm{N}_{2}$ production; denitrification, which reduces $\mathrm{NO}_{3}{ }^{-}$ through a series of intermediates to $\mathrm{N}_{2}$, and anammox, which forms $\mathrm{N}_{2}$ by directly coupling $\mathrm{NO}_{2}{ }^{-}$with $\mathrm{NH}_{4}{ }^{+}$. Organisms responsible for denitrification and anammox proliferate in $\mathrm{O}_{2}$ minimum zones (OMZs) of the modern oceans, which support $20-40 \%$ of global fixed $\mathrm{N}$ loss to the atmosphere ${ }^{2}$.

Under the well-oxygenated modern atmosphere, OMZs $\left(\mathrm{O}_{2}<20 \mu \mathrm{moll}^{-1}\right)$ comprise $7 \%$ by volume of the global ocean ${ }^{3}$, and their anoxic cores, which sustain most fixed $\mathrm{N}$ loss, occupy only $0.1 \%{ }^{2}$. During the Proterozoic eon, however, atmospheric $\mathrm{O}_{2}$ levels were lower than today and vast regions of the ocean were anoxic ${ }^{4}$. Loss of fixed $\mathrm{N}$ is predicted under ocean anoxia and such expansive anoxia could have led to extreme $\mathrm{N}$ limitation ${ }^{5}$. N isotope distributions from Palaeoproterozoic upwelling systems, however, imply relatively little fixed $\mathrm{N}$ loss ${ }^{6}$. This suggests either modest rates of denitrification or $\mathrm{N}$ retention, possibly through reduction of $\mathrm{NO}_{3}{ }^{-}$to $\mathrm{NH}_{4}{ }^{+6}$. Notably, anoxia and a supply of $\mathrm{NO}_{3}{ }^{-}$will not support fixed $\mathrm{N}$ loss without electron donors to drive denitrification, or $\mathrm{NH}_{4}{ }^{+}$to support anammox. In the modern ocean, denitrification is fuelled through both organic electron donors and $\mathrm{H}_{2} \mathrm{~S}$ (refs 7,8). Organic electron donors may have been scarce under the generally low productivity of Proterozoic oceans ${ }^{5}$, and $\mathrm{H}_{2} \mathrm{~S}$ would have been scarce except during episodic euxinic periods that punctuate the Proterozoic geologic record ${ }^{6,9-12}$. Ferruginous conditions were much more prevalent than euxinia, dominating ocean chemistry throughout the Proterozoic ${ }^{13}$. Ferrous $\mathrm{Fe}(\mathrm{Fe}(\mathrm{II}))$ is known to support $\mathrm{NO}_{3}{ }^{-}$reduction in laboratory experiments ${ }^{14,15}$ but the environmental operation, significance and pathways of $\mathrm{Fe}$-dependent $\mathrm{NO}_{3}{ }^{-}$reduction remain untested in natural ferruginous water columns.

Kabuno Bay $(\mathrm{KB})$ is a ferruginous sub-basin of Lake Kivu, which straddles the border of Rwanda and the Democratic Republic of Congo, East Africa ${ }^{16}$. Saline springs feed KB causing permanent stratification, anoxia below $10 \mathrm{~m}$ (Fig. 1a,b), and Fe(II)-rich deep waters $(\approx 500 \mu \mathrm{M}-$ Fig. $1 \mathrm{~d})$. Such ferruginous conditions are analogous to those that prevailed through much of the Proterozoic eon ${ }^{16}$. A strong gradient of $\mathrm{NH}_{4}{ }^{+}$between 10 and $11.5 \mathrm{~m}$ depth (Fig. 1c) indicates high rates of $\mathrm{NH}_{4}{ }^{+}$oxidation to $\mathrm{NO}_{3}{ }^{-}$and $\mathrm{NO}_{2}^{-}$ within this depth interval. Since KB's oxic surface waters are devoid of $\mathrm{NO}_{3}{ }^{-}$and $\mathrm{NO}_{2}{ }^{-}$(concentrations $<1 \mu \mathrm{M}$ ), $\mathrm{NO}_{3}{ }^{-}$and $\mathrm{NO}_{2}{ }^{-}$ produced through $\mathrm{NH}_{4}{ }^{+}$oxidation are advected to the main basin, assimilated, or rapidly reduced.

We determined rates and pathways of microbial $\mathrm{N}$ transformations in $\mathrm{KB}$ using incubations with ${ }^{15} \mathrm{~N}$-labelled $\mathrm{NO}_{3}{ }^{-}$. Both denitrification and dissimilatory nitrate reduction to ammonium (DNRA) occur between 11 and $11.5 \mathrm{~m}$, but anammox was below

\footnotetext{
${ }^{1}$ Microbiology \& Immunology, and Earth, Ocean, \& Atmospheric Sciences Departments, University of British Columbia, Vancouver, BC V6T 1Z3, Canada. ${ }^{2}$ Chemical Oceanography Unit, Université de Liège, 4000 Liège, Belgium. ${ }^{3}$ Department of Earth \& Environmental Sciences, KU Leuven, 3001 Leuven, Belgium. ${ }^{4}$ Department of Genetics and Microbiology, Universitat Autònoma de Barcelona, 08193 Barcelona, Spain. ${ }^{5}$ Institute of Life Sciences (ISV), Université Catholique de Louvain, 1348 Louvain-la-Neuve, Belgium. ${ }^{6}$ Ecologie des Systèmes Aquatiques, Université Libre de Bruxelles, 1050 Bruxelles, Belgium. ${ }^{7}$ Institute of Biology, Nordic Center for Earth Evolution, University of Southern Denmark, 5230 Odense, Denmark. ${ }^{8}$ Research Unit in Environmental and Evolutionary Biology (URBE), University of Namur, 5000 Namur, Belgium. *e-mail: sean.crowe@ubc.ca
} 
a

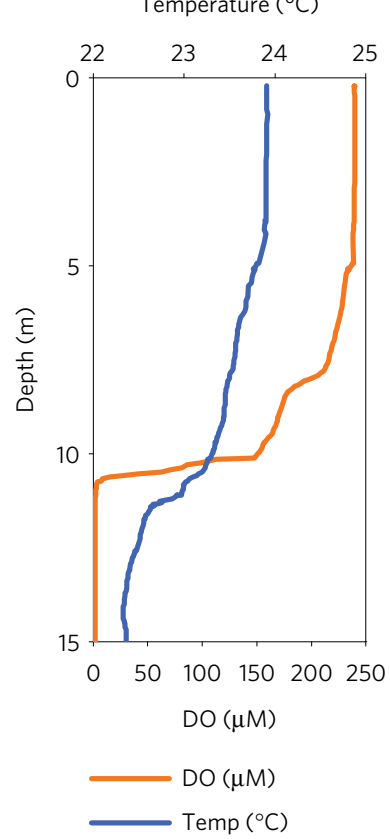

b

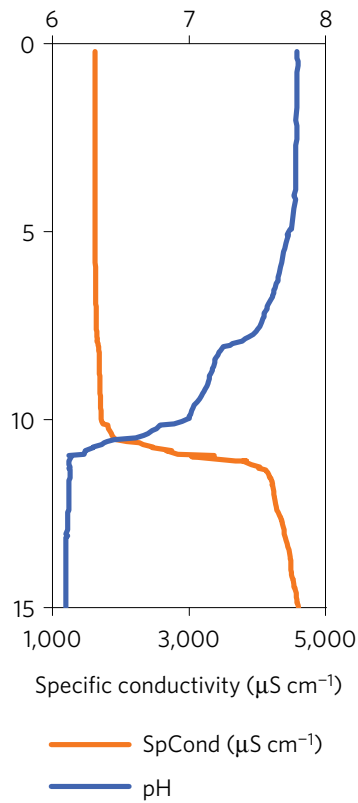

c

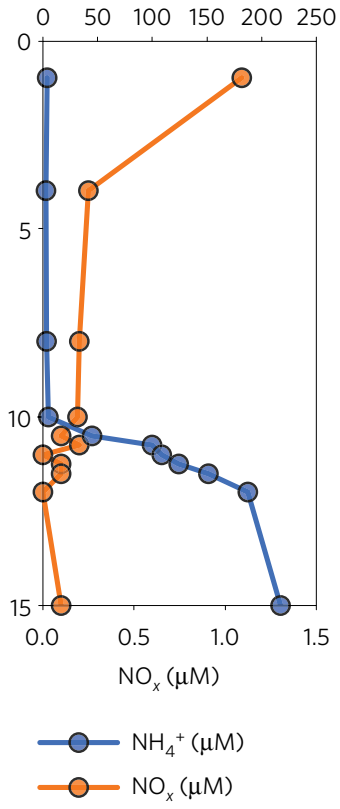

d Fe (II) and (III) particulate ( $\mu \mathrm{M})$

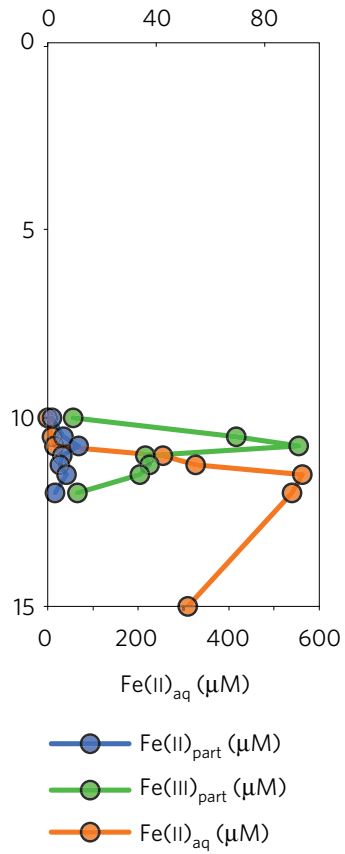

Figure 1 | Vertical distribution of selected physical and chemical properties of Kabuno Bay for February 2012. a, Dissolved $\mathrm{O}_{2}(\mathrm{DO})$ concentration $(\mu M)$ and temperature $\left({ }^{\circ} \mathrm{C}\right) \cdot \mathbf{b}, \mathrm{pH}$ and specific conductivity $\left(\mathrm{SpCond}, \mu \mathrm{S} \mathrm{cm}^{-1}\right)$. c, $\mathrm{NH}_{4}{ }^{+}$and $\mathrm{NO}_{x}$ concentration $(\mu \mathrm{M}) . \mathbf{d}, \mathrm{Fe}(\mathrm{II})_{\text {aq }}, \mathrm{Fe}(\mathrm{II})_{\text {part }}$ and Fe$(\mathrm{III})_{\text {part }}$ concentrations $(\mu \mathrm{M})$.

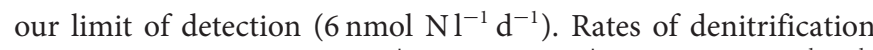

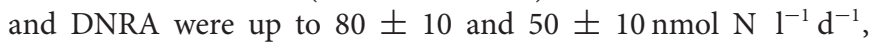
respectively (Fig. 2a,b and Supplementary Table 3), exceeding those typically found in marine $\mathrm{OMZs}^{8,17}$ but similar to coastal marine anoxic basins such as the Baltic Sea ${ }^{18}$. While $60 \%$ of $\mathrm{NO}_{3}{ }^{-}$reduced is lost from the $\mathrm{KB}$ through denitrification, $40 \%$ is retained as $\mathrm{NH}_{4}{ }^{+}$ through DNRA. Substantial $\mathrm{NO}_{3}{ }^{-}$recycling to $\mathrm{NH}_{4}{ }^{+}$has also been periodically observed in the Peruvian and Omani OMZs ${ }^{17,19}$, but such a high fraction appears to be unusual for modern pelagic marine environments ${ }^{8,20}$. Our observations imply that some biogeochemical feature of KB favours DNRA compared with other environments studied to date. Fe(II), which is unusually abundant in $\mathrm{KB}$, indeed promotes DNRA in estuarine sediment ${ }^{21}$, and may also do so in $\mathrm{KB}$.

To test for such Fe dependency, we amended a subset of our ${ }^{15} \mathrm{~N}$ incubations with $40 \mu \mathrm{M}$ Fe(II). We found that $\mathrm{Fe}$ (II) addition considerably enhanced both denitrification and DNRA to $230 \pm 40$ and $70 \pm 20 \mathrm{nmol} \mathrm{N}^{-1} \mathrm{~d}^{-1}$, respectively (Fig. 2a,b and Supplementary Table 3), suggesting a role for $\mathrm{Fe}(\mathrm{II})$ in $\mathrm{NO}_{3}{ }^{-}$ reduction. Our results support measurements from estuarine sediments, which invoke microbial mediation ${ }^{21}$, but the nearly equivalent stimulation between both $\mathrm{NO}_{3}{ }^{-}$reduction to $\mathrm{NH}_{4}{ }^{+}$ and denitrification provides no evidence that $\mathrm{Fe}$ (II) favours DNRA and instead may indicate that $\mathrm{Fe}$ (II) enhances the reduction of an intermediate (for example, $\mathrm{NO}_{2}{ }^{-}$) common to both reactions. Thermodynamic considerations reveal that reduction of $\mathrm{NO}_{3}{ }^{-}$, and a number of intermediate $\mathrm{N}$ species, by $\mathrm{Fe}(\mathrm{II})$ is energetically favourable in $\mathrm{KB}$ (see Supplementary Information) yielding sufficient free energy for microbial growth. While the precise pathway remains unresolved, $\mathrm{Fe}(\mathrm{II})$ clearly plays a role in $\mathrm{NO}_{3}{ }^{-}$ reduction in $\mathrm{KB}$.

To assess the biogeochemical role of Fe-dependent $\mathrm{NO}_{3}{ }^{-}$reduction in $\mathrm{KB}$, we compared rates of $\mathrm{NO}_{3}^{-}$reduction with other key processes ${ }^{16}$. While $\mathrm{Fe}(\mathrm{II})$ supports $\mathrm{NO}_{3}{ }^{-}$reduction, the corresponding $\mathrm{Fe}(\mathrm{II})$ oxidation rates of $1,700 \mathrm{nmol} \mathrm{Fe}^{-1} \mathrm{~d}^{-1}$ (based on stoichiometry) are only a minor fraction (1\%) of the observed phototrophic $\mathrm{Fe}(\mathrm{II})$ oxidation in the $\mathrm{KB}$ chemocline ${ }^{16}$. By comparison, $\mathrm{NO}_{3}{ }^{-}$reduction rates are an order of magnitude lower than $\mathrm{SO}_{4}{ }^{2-}$ reduction rates, which are up to $410 \mathrm{nmol} \mathrm{Sl}^{-1} \mathrm{~d}^{-1}$ (ref. 16). We also compared rates of $\mathrm{NO}_{3}{ }^{-}$reduction with dark carbon fixation, and on the basis of growth yields for chemoautotrophic $\mathrm{NO}_{3}{ }^{-}$reduction (see Supplementary Information), this comparison suggests that $\mathrm{NO}_{3}{ }^{-}$-driven chemoautotrophy could support up to $2 \%$ of the total dark carbon fixation in KB's water column ${ }^{16}$. The overall contribution of $\mathrm{NO}_{3}{ }^{-}$reduction to biogeochemical cycling, therefore, is largely to regulate recycling and loss of fixed $\mathrm{N}$ from $\mathrm{KB}$, and here, the partitioning of $\mathrm{NO}_{3}{ }^{-}$reduction between DNRA and denitrification is key.

We have shown that $\mathrm{NO}_{3}{ }^{-}$reduction both to $\mathrm{N}_{2}$ and $\mathrm{NH}_{4}{ }^{+}$ takes place at relatively high rates under ferruginous conditions, and further, that this $\mathrm{NO}_{3}{ }^{-}$reduction is partly coupled to the oxidation of $\mathrm{Fe}(\mathrm{II})$. By extension, the ferruginous oceans of the Proterozoic eon could also have supported large-scale $\mathrm{NO}_{3}{ }^{-}$reduction, possibly through both denitrification and DNRA, and with Fe(II) as the electron donor ${ }^{5,22}$. To quantitatively link our observations in $\mathrm{KB}$ to possible biogeochemical cycling under ancient marine ferruginous conditions, we set up a box model for $\mathrm{N}$ cycling in ocean upwelling systems $^{23,24}$. Our model describes mass balances for C, N, S, O and $\mathrm{Fe}$ species and their biogeochemical reactions (see Fig. 3a and full description in the Supplementary Information). $\mathrm{NH}_{4}^{+}$and Fe were supplied through upwelling, and these, along with nutrient recycling, ultimately controlled primary production in the overlying surface waters. Production in the surface waters is sustained exclusively through upwelled $\mathrm{N}$ with no productivity by local $\mathrm{N}$ fixation. Settling of organic matter generated through primary production drives respiration and nutrient recycling in intermediate waters. Chemotrophic processes such as nitrification, and $\mathrm{Fe}$ dependent denitrification and DNRA were included (Fig. 3a). Our model is based on previous studies ${ }^{23,24}$, but we considered a ferruginous system where $\mathrm{N}$ cycling was driven first by $\mathrm{Fe}-$ dependent $\mathrm{NO}_{3}{ }^{-}$reduction, with the remaining $\mathrm{NO}_{3}{ }^{-}$reduced by organic matter originating through primary production (Fig. 3a). 
a

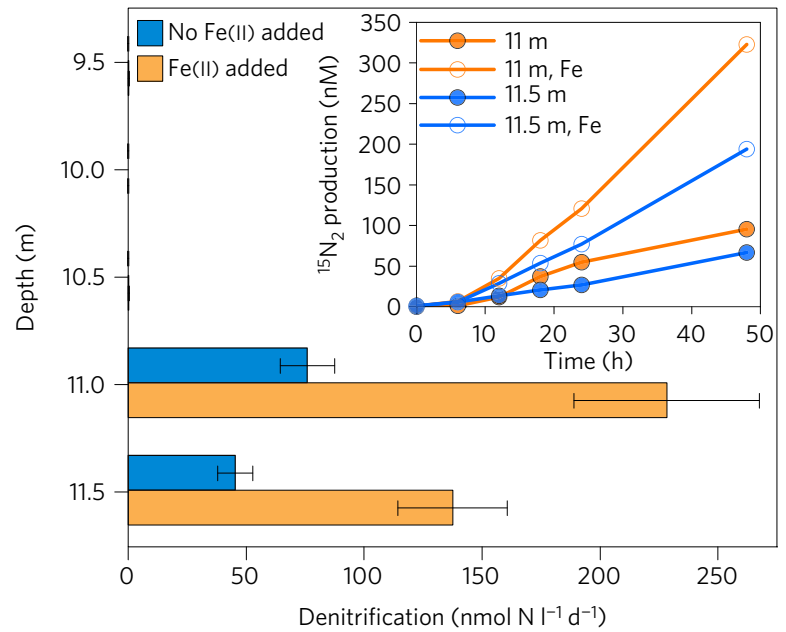

b

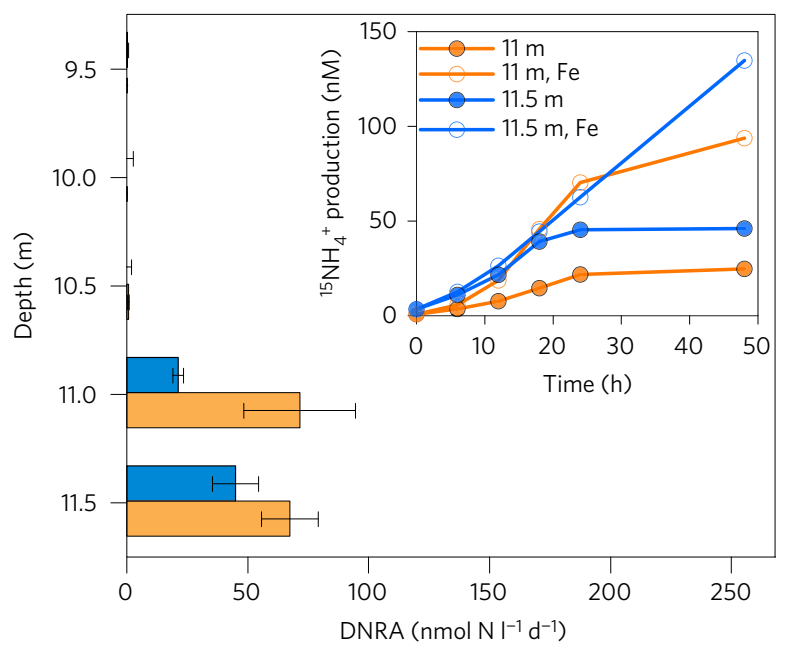

Figure 2 | Rates and pathways in Kabuno Bay for February 2012. $\mathbf{a}, \mathbf{b}$, Denitrification (a) and DNRA (b) in Kabuno Bay water column. Samples were collected in February 2012, with (in orange) or without (in blue) addition of the electron donor Fe(II) to the incubations. Insets show time-course evolution of ${ }^{15} \mathrm{~N}$-labelled metabolic products. Rates were calculated on the basis of linear regressions over the linear data intervals ( 24 or $48 \mathrm{~h}$ ). Supplementary Table 3 contains the detailed rates and associated errors. The error on the rate is the standard error of the slope for the linear regression.

We also included DNRA, in accordance with our results from $\mathrm{KB}$, to evaluate its impact on coupled $\mathrm{C}, \mathrm{N}, \mathrm{Fe}$ and $\mathrm{S}$ cycling under ferruginous conditions. Without explicit constraints on the fraction of $\mathrm{NO}_{3}{ }^{-}$reduced to $\mathrm{NH}_{4}{ }^{+}$versus $\mathrm{N}_{2}$ in ferruginous oceans, we varied its contribution from 0 to $40 \%$, with the balance occurring through denitrification.

Deep-ocean $\mathrm{Fe}$ (II) and $\mathrm{NH}_{4}{ }^{+}$concentrations throughout the Proterozoic eon are uncertain. If global $\mathrm{N}$ fixation is limited by phosphorous supply according to the Redfield ratio (16N:1P; ref. 25), we can set deep-ocean $\mathrm{NH}_{4}{ }^{+}$concentrations in our model at 16 times the phosphorous concentration $(0.04-0.13 \mu \mathrm{M})$ of Proterozoic seawater ${ }^{26}$ (see Supplementary Information), which yields up to $2 \mu \mathrm{M} \mathrm{NH}_{4}{ }^{+}$. To validate this assumption, we excluded DNRA and ran our model with different ratios of N/P in deep waters. When deep ocean $\mathrm{NH}_{4}{ }^{+}$is greater than $13 \mu \mathrm{M}$, sulfidic conditions develop without DNRA or $\mathrm{N}$ fixation under all reasonable upwelling rates ${ }^{23}$ (Fig. 3e). Thus, if deep-ocean $\mathrm{NH}_{4}{ }^{+}$ concentrations were more than $13 \mu \mathrm{M}$, sulfidic conditions would have been widespread during the Proterozoic eon. Such widespread euxinia is not supported by the geologic record ${ }^{13}$, indicating that $\mathrm{NH}_{4}{ }^{+}$concentrations were generally less than $13 \mu \mathrm{M}$ in the deep ocean. We thus chose $2 \mu \mathrm{M} \mathrm{NH}_{4}{ }^{+}$as the benchmark for our modelling, but also explored a concentration range from 0.6 through to $13 \mu \mathrm{M}$. In line with considerations for both siderite solubility ${ }^{27}$ and nutrient dynamics that permit marine oxygenic photosynthesis ${ }^{26}$ we chose $42 \mu \mathrm{M}$ as our benchmark $\mathrm{Fe}$ (II) concentration (see Supplementary Information). We also considered a broader range of Fe(II) concentrations (see Supplementary Information), which may be possible if siderite formation was kinetically inhibited ${ }^{28}$.

Our model shows that in ferruginous upwelling systems the balance between DNRA and denitrification strongly influences coupled C, N, S and Fe cycling with enhanced primary production when DNRA is an appreciable $\mathrm{NO}_{3}{ }^{-}$reduction pathway. Indeed, when $40 \%$ of $\mathrm{NO}_{3}{ }^{-}$reduction is channelled through DNRA, primary production rates increase by up to $170 \%$ (Fig. 3b,c). A notable effect of this enhanced primary production is greatly increased $\mathrm{H}_{2} \mathrm{~S}$ production. This occurs even in the absence of $\mathrm{N}$ fixation as DNRA provides the nitrogen to stimulate additional organic matter production, which ultimately fuels microbial sulfate reduction (see Supplementary Information). At 40\% DNRA, strong upwelling leads to sulfate reduction and pyrite deposition at rates sufficient to yield sediment iron speciation $\left(\mathrm{Fe}_{\mathrm{py}} / \mathrm{Fe}_{\mathrm{HR}}\right.$ ) that indicates possible water column euxinia. Such $\mathrm{Fe}_{\mathrm{py}} / \mathrm{Fe}_{\mathrm{HR}}$ values $(>0.7)$ exist in Proterozoic sedimentary rocks ${ }^{6,9-12}$, which could thus record a contribution of DNRA to $\mathrm{NO}_{3}{ }^{-}$reduction at this time.

Our model also reveals a negative feedback between primary production and surface ocean oxygen. This negative feedback develops when $\mathrm{N}$ loss increases in response to enhanced $\mathrm{NO}_{3}{ }^{-}$ supply due to stimulation of nitrification by $\mathrm{O}_{2}$. An increase from $3.8 \%$ to $6.2 \%$ PAL (present atmospheric level) $\mathrm{O}_{2}$, values thought possible for the Mesoproterozoic ${ }^{29}$ (values as low as $0.1 \%$ PAL have been proposed $\left.{ }^{30}\right)$, reduces primary production by up to $20 \%$ when $\mathrm{NO}_{3}{ }^{-}$reduction occurs exclusively through denitrification. This effect is muted by DNRA (Fig. 3b,c), which can play an increasingly important role in supplying $\mathrm{N}$ for primary production with the progressive oxygenation of the surface ocean (Fig. 3d).

It is widely assumed that the Proterozoic oceans were $\mathrm{N}$ limited due to massive $\mathrm{N}$ loss $^{5}$. While the euphotic waters directly overlying upwelling systems can be locally $\mathrm{N}$ limited due to $\mathrm{N}$ loss from below, the global expression of $\mathrm{N}$ limitation ultimately depends on the balance between the geographic expansiveness of upwelling systems, and ocean-wide $\mathrm{N}$ fixation. We extrapolated $\mathrm{N}$ loss from our model to an area equivalent to upwelling regions in the modern ocean $\left(0.3610^{12} \mathrm{~m}^{2}\right)^{31}$ yielding a modelled global $\mathrm{N}$ loss from Proterozoic oceans of up to $1.6 \mathrm{Tg} \mathrm{N} \mathrm{yr}^{-1}$ (see Supplementary Information). By comparison, Proterozoic phosphorous concentrations ${ }^{26}$ could have supported $4.8 \mathrm{Tg}$ of $\mathrm{N}$ fixation per year based on an equivalent ratio of $\mathrm{N}$ fixed to deep ocean phosphorous as in the modern ocean ${ }^{25}$ (see Supplementary Information). It has also been proposed that molybdenum (Mo) limited $\mathrm{N}$ fixation due to its scavenging from seawater as sulfide minerals ${ }^{32}$. Mo limitation seems unlikely, as Mo scavenging from seawater generally requires strong euxinia (see Supplementary Information), which as we show here, would not likely have developed in Proterozoic upwelling systems. To balance global $\mathrm{N}$ fixation with $\mathrm{N}$ loss in the Proterozoic eon, an upwelling area three times that of the modern ocean would have been needed. This suggests that $\mathrm{N}$ limitation in the Proterozoic was unlikely and that productivity would, instead, have been limited by phosphorous. Our modelling results are well supported by the Palaeoproterozoic rock record ${ }^{6}$, which implies upwelling systems with euxinic conditions (possibly supported by DNRA) that induce little fixed $\mathrm{N}$ loss (also possibly the result of DNRA). The operation of these processes throughout the Proterozoic eon can be further tested through an expansion of the $\mathrm{N}$ isotope record, and through simulations in global biogeochemical models informed by our data. 
a

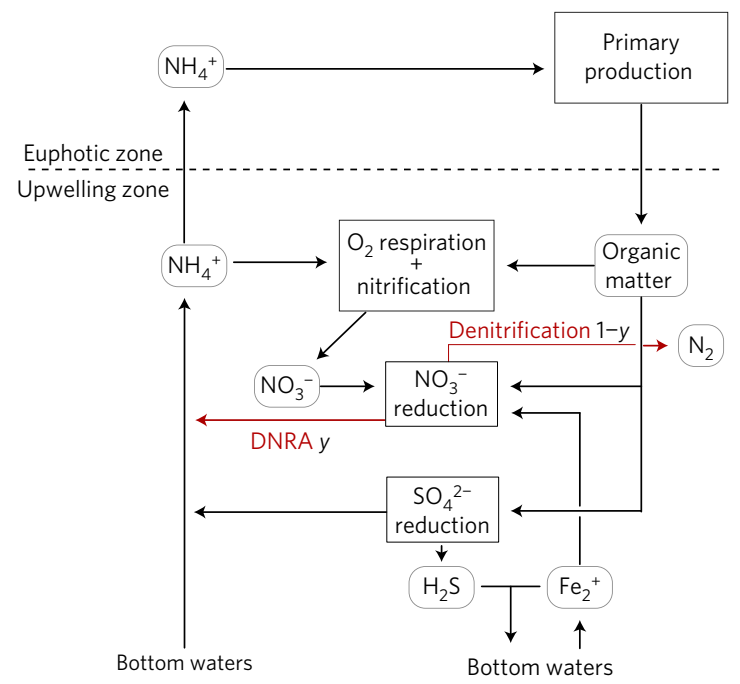

d

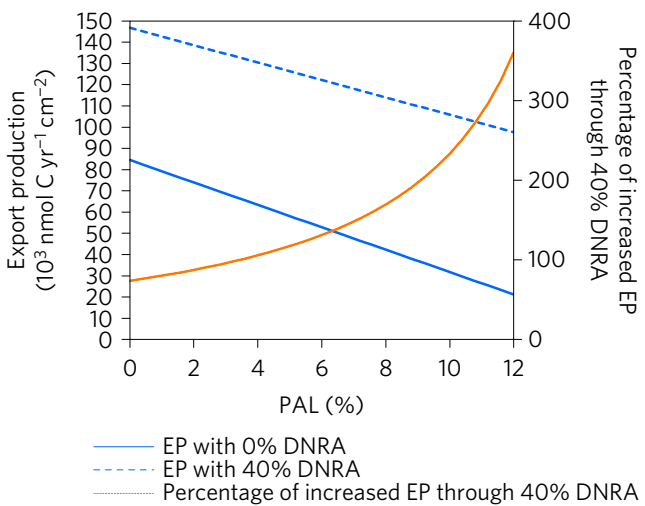

b
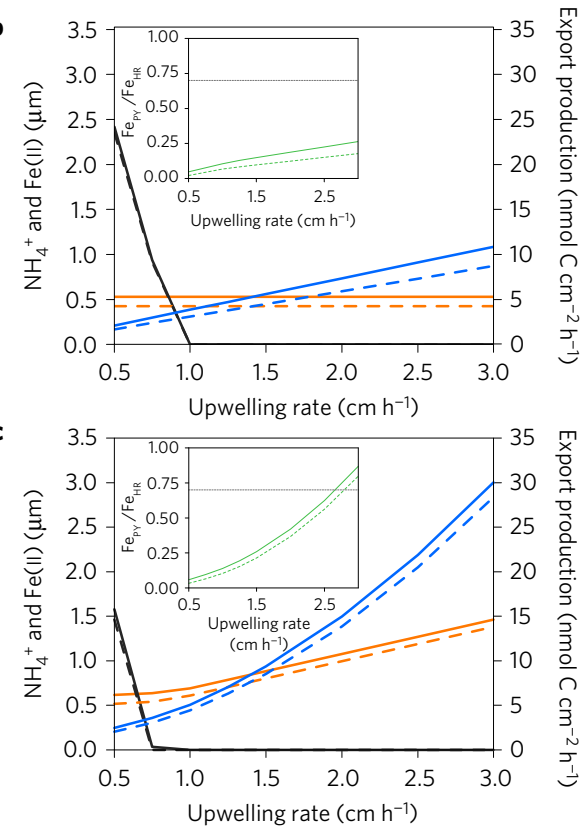

e

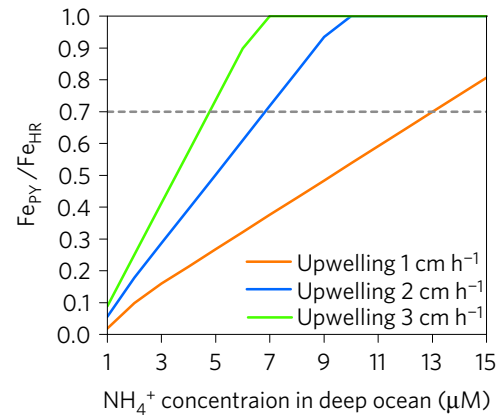

Figure 3 | Model outputs describing coupled C, N, S and Fe cycling in an idealized Proterozoic upwelling system. a, Model structure illustrating reactions included and their reactants and products. b,c, Model runs with $0 \%(\mathbf{b})$ and $40 \% \mathrm{NO}_{3}{ }^{-}$reduction (c) through DNRA. The solid lines represent model runs

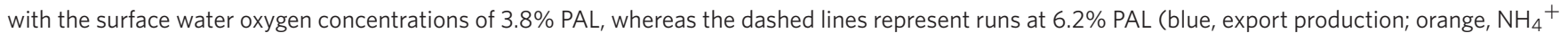
concentrations in the upwelling zone; black, $\mathrm{Fe}(\mathrm{II})$ concentrations in the upwelling zone; the insets show the Fe pyrite to highly reactive Fe ratio (FepY/Fe $\mathrm{HR}$ ) where the grey line delineates plausible euxinic conditions ${ }^{13}$ ). d, Yearly export production (EP) for $0 \%$ and $40 \%$ DNRA for a range of surface waters oxygen concentrations (from 0 to $12 \% \mathrm{PAL}$ ) at an upwelling rate of $2 \mathrm{~cm} \mathrm{~h}^{-1}$. At $\mathrm{O} \% \mathrm{PAL}$, nitrification is not present in our model; however, $\mathrm{NO}_{3}{ }^{-}$is still supplied from the intermediate waters, therefore feeding $\mathrm{NO}_{3}{ }^{-}$reduction through DNRA and denitrification (see Supplementary Information). e, FepY/Fe $\mathrm{HR}$ ratios for a range of deep-ocean $\mathrm{NH}_{4}{ }^{+}$concentrations at 0\% DNRA for three different upwelling rates at 3.8\% PAL (the grey dashed line delineates plausible euxinic conditions ${ }^{13}$ ). See Supplementary Information for details.

\section{Methods}

Methods, including statements of data availability and any associated accession codes and references, are available in the online version of this paper.

Received 17 July 2016; accepted 22 December 2016; published online 30 January 2017

\section{References}

1. Vitousek, P. M. Human domination of Earth's ecosystems. Science 277, 494-499 (1997).

2. Codispoti, L. A. et al. The oceanic fixed nitrogen and nitrous oxide budgets: Moving targets as we enter the anthropocene? Sci. Mar. 65, 85-105 (2001).

3. Paulmier, A. \& Ruiz-Pino, D. Oxygen minimum zones (OMZs) in the modern ocean. Prog. Oceanogr. 80, 113-128 (2009).

4. Canfield, D. E. A new model for Proterozoic ocean chemistry. Nature 396, 450-453 (1998).

5. Fennel, K., Follows, M. \& Falkowski, P. G. The co-evolution of the nitrogen, carbon and oxygen cycles in the Proterozoic ocean. Am. J. Sci. 305, 526-545 (2005).
6. Godfrey, L. V., Poulton, S. W., Bebout, G. E. \& Fralick, P. W. Stability of the nitrogen cycle during development of sulfidic water in the redox-stratified late Paleoproterozoic Ocean. Geology 41, 655-658 (2013).

7. Canfield, D. E. et al. A cryptic sulfur cycle in oxygen-minimum-zone waters off the Chilean coast. Science 330, 1375-1378 (2010).

8. Kalvelage, T. et al. Nitrogen cycling driven by organic matter export in the South Pacific oxygen minimum zone. Nat. Geosci. 6, 228-234 (2013).

9. Johnston, D. T. et al. An emerging picture of Neoproterozoic ocean chemistry: insights from the Chuar Group, Grand Canyon, USA. Earth Planet. Sci. Lett. 290, 64-73 (2010).

10. Li, C. et al. A stratified redox model for the Ediacaran ocean. Science 328, 80-83 (2010).

11. Poulton, S. W., Fralick, P. W. \& Canfield, D. E. Spatial variability in oceanic redox structure 1.8 billion years ago. Nat. Geosci. 3, 486-490 (2010).

12. Reinhard, C. T., Raiswell, R., Scott, C., Anbar, A. D. \& Lyons, T. W. A late archean sulfidic sea stimulated by early oxidative weathering of the continents. Science 326, 713-716 (2009).

13. Poulton, S. W. \& Canfield, D. E. Ferruginous conditions: a dominant feature of the ocean through earth's history. Elements 7, 107-112 (2011)

14. Straub, K. L., Benz, M., Schink, B. \& Widdel, F. Anaerobic, nitrate-dependent microbial oxidation of ferrous iron. Appl. Environ. Microbiol. 62, 1458-1460 (1996). 
15. Weber, K. A., Urrutia, M. M., Churchill, P. F., Kukkadapu, R. K. \& Roden, E. E. Anaerobic redox cycling of iron by freshwater sediment microorganisms. Environ. Microbiol. 8, 100-113 (2006).

16. Lliros, M. et al. Pelagic photoferrotrophy and iron cycling in a modern ferruginous basin. Sci. Rep. 5, 13803 (2015).

17. Lam, P. et al. Revising the nitrogen cycle in the Peruvian oxygen minimum zone. Proc. Natl Acad. Sci. USA 106, 4752-4757 (2009).

18. Jensen, M. M., Petersen, J., Dalsgaard, T. \& Thamdrup, B. Pathways, rates, and regulation of $\mathrm{N}_{2}$ production in the chemocline of an anoxic basin, Mariager Fjord, Denmark. Mar. Chem. 113, 102-113 (2009).

19. Jensen, M. M. et al. Intensive nitrogen loss over the Omani Shelf due to anammox coupled with dissimilatory nitrite reduction to ammonium. ISME J. 5, 1660-1670 (2011).

20. De Brabandere, L. et al. Vertical partitioning of nitrogen-loss processes across the oxic-anoxic interface of an oceanic oxygen minimum zone. Environ. Microbiol. 16, 3041-3054 (2014).

21. Robertson, E. K., Roberts, K. L., Burdorf, L. D. W., Cook, P. \& Thamdrup, B. Dissimilatory nitrate reduction to ammonium coupled to Fe(II) oxidation in sediments of a periodically hypoxic estuary. Limnol. Oceanogr. 61, 365-381 (2016)

22. Canfield, D. E., Rosing, M. T. \& Bjerrum, C. Early anaerobic metabolisms. Phil. Trans. R Soc. B 361, 1819-1834 (2006).

23. Canfield, D. E. Models of oxic respiration, denitrification and sulfate reduction in zones of coastal upwelling. Geochim. Cosmochim. Acta 70, 5753-5765 (2006)

24. Boyle, R. A. et al. Nitrogen cycle feedbacks as a control on euxinia in the mid-Proterozoic ocean. Nat. Commun. 4 (2013).

25. Tyrrell, $\mathrm{T}$. The relative influences of nitrogen and phosphorus on oceanic primary production. Nature 400, 525-531 (1999).

26. Jones, C., Nomosatryo, S., Crowe, S. A., Bjerrum, C. J. \& Canfield, D. E. Iron oxides, divalent cations, silica, and the early earth phosphorus crisis. Geology 43, 135-138 (2015).

27. Holland, H. D. The Chemical Evolution of the Atmosphere and Oceans (Princeton Univ. Press, 1984).

28. Derry, L. A. Causes and consequences of mid-Proterozoic anoxia. Geophys. Res. Lett. 42, 8538-8546 (2015).
29. Zhang, S. et al. Sufficient oxygen for animal respiration 1,400 million years ago. Proc. Natl Acad. Sci. USA 113, 1731-1736 (2016).

30. Planavsky, N. J. et al. Low Mid-Proterozoic atmospheric oxygen levels and the delayed rise of animals. Science 346, 635-638 (2014).

31. Martin, J. H., Knauer, G. A., Karl, D. M. \& Broenkow, W. W. Vertex-carbon cycling in the northeast Pacific. Deep-Sea Res. 34, 267-285 (1987).

32. Anbar, A. D. \& Knoll, A. H. Proterozoic ocean chemistry and evolution: a bioinorganic bridge? Science 297, 1137-1142 (2002).

\section{Acknowledgements}

The authors thank G. Alunga, P. Masilya, P. M. Ishumbisho, B. Kaningini, C. Balagizi, K. Karume, M. Yalire, Djoba, Silas, L. Nyinawamwiza, B. Leporcq, A. Anzil,

M.-V. Commarieu, C. Wiking-Antiviakis and L. De Brabandere for help with laboratory and field work. This work was partially supported by Agouron Institute and NSERC discovery grants to S.A.C., and Belgian (FNRS2.4.515.11 and BELSPO SD/AR/02A contracts), Danish (grant no. DNRF53 to D.E.C.) and European (grant no. ERC-StG 240002 , for stable isotope measurements) funds. A.V.B. is a senior research associate at the FRS-FNRS. C. Reinhard provided insightful comments.

\section{Author contributions}

F.D., A.V.B., C.C.M. and S.A.C. designed the experiments. F.D., F.A.E.R., S.A.C. and C.C.M. carried out the experiments. C.C.M. and S.A.C. analysed data and developed the model. C.C.M. and S.A.C. co-wrote the paper. All of the authors contributed to the revision of the paper.

\section{Additional information}

Supplementary information is available in the online version of the paper. Reprints and permissions information is available online at www.nature.com/reprints. Correspondence and requests for materials should be addressed to S.A.C.

\section{Competing financial interests}

The authors declare no competing financial interests. 


\section{Methods}

Physico-chemical parameters as well as ${ }^{15} \mathrm{~N}$-labelled incubations were performed during a sampling expedition to Kabuno Bay (Lake Kivu, East Africa $-1.58^{\circ}-1.70^{\circ} \mathrm{S}$, $29.01^{\circ}-29.09^{\circ} \mathrm{E}$ ) in February 2012. In situ vertical conductivity-temperature-depth (CTD) profiles were collected via two multi-parameter probes (Hydrolab DS5, OTT Hydromet; and Sea\&Sun CTD90, Sea and Sun Technology). $\mathrm{NO}_{2}{ }^{-}$ and $\mathrm{NH}_{4}{ }^{+}$concentrations were measured spectrophotometrically ${ }^{33}$. Additionally, $\mathrm{NO}_{3}{ }^{-}$concentrations were determined by subtracting $\mathrm{NO}_{2}{ }^{-}$from the $\mathrm{NO}_{x}\left(\mathrm{NO}_{3}{ }^{-}\right.$ and $\mathrm{NO}_{2}{ }^{-}$) measurements (via chemiluminescence ${ }^{34}$ ). $\mathrm{Fe}$ speciation was measured according to ref. $35 . \mathrm{H}_{2} \mathrm{~S}$ and $\mathrm{SO}_{4}{ }^{2-}$ concentrations were determined using the Cline method ${ }^{33}$ and ion chromatography (Dionex), respectively. ${ }^{15} \mathrm{~N}$-labelled incubations were performed in duplicate in $12 \mathrm{ml}$ Exetainers, allowing water to be incubated under anoxic conditions. Microbial activity was arrested with $\mathrm{ZnCl}_{2}$ at several time points for each experiment. The ${ }^{15} \mathrm{~N}-\mathrm{N}_{2}$ and ${ }^{15} \mathrm{~N}-\mathrm{NH}_{4}{ }^{+}$produced was quantified with isotopic ratio mass spectrometry. Rates of DNRA, denitrification and anammox were determined according to ref. 36 . Rates were calculated on the basis of linear regressions with the least-squares method over the most linear data intervals ( 24 or $48 \mathrm{~h}$ ). The structure of the box model set-up here is the same as that developed in ref. 23 and adapted for the Proterozoic eon in ref. 24. Details on model parameters can be found in the Supplementary Information.
Code availability. Our model was produced using Microsoft Office Excel. It is entirely reproducible using the information available in both the main text and the supplementary section.

Data availability. The authors declare that the data supporting the findings of this study are available within the article and its Supplementary Information files.

\section{References}

33. Grasshoff, K., Ehrhardt, M., Kremling, K. \& Anderson, L. G. Methods of Seawater Analysis 3rd edn (Wiley, 1999).

34. Fontijn, A., Sabadell, A. J. \& Ronco, R. J. Homogeneous chemiluminescent measurement of nitric oxide with ozone-implications for continuous selective monitoring of gaseous air pollutants. Anal. Chem. 42, 575-579 (1970).

35. Viollier, E., Inglett, P. W., Hunter, K., Roychoudhury, A. N. \& Van Cappellen, P. The ferrozine method revisited: $\mathrm{Fe}(\mathrm{II}) / \mathrm{Fe}(\mathrm{III})$ determination in natural waters. Appl. Geochem. 15, 785-790 (2000).

36. Thamdrup, B. et al. Anaerobic ammonium oxidation in the oxygen-deficient waters off northern Chile. Limnol. Oceanogr. 51, 2145-2156 (2006). 